\title{
PENGARUH PELAYANAN, IKLAN DAN PUBLISITAS TERHADAP KEPUTUSAN NASABAH DALAM MENABUNG DI BANK BRI SYARIAH
}

Siti Fatimah ${ }^{\text {a }}$ *Shelly Midesia ${ }^{\mathrm{b}}$ Fahriansah $^{\mathrm{c}}$

${ }^{a, b, c}$ Fakultas Ekonomi dan Bisnis Islam, IAIN Langsa

b*Email : shellymidesia@iainlangsa.ac.id

\begin{abstract}
Abstrak
Penelitian ini bertujuan untuk mengetahui pengaruh pelayanan, iklan, dan publisitas terhadap keputusan nasabah dalam menabung di Bank BRI Syariah. Metode pengambilan sampel dalam penelitian ini dengan menggunakan random sampling dengan jumlah sampel sebanyak 100 nasabah Bank BRI Syariah Stabat Kabupaten Langkat. Metode analisis data yang digunakan adalah analisis regresi linear berganda. Hasil penelitian yang diuji secara parsial menunjukkan bahwa pelayanan dan iklan berpengaruh signifikan terhadap keputusan nasabah dalam menabung di Bank BRI Syariah, sedangkan publisitas tidak berpengaruh signifikan terhadap keputusan nasabah dalam menabung di Bank BRI Syariah. Pengujian secara simultan menunjukkan bahwa pelayanan, iklan, dan publisitas berpengaruh signifikan terhadap keputusan nasabah dalam menabung di Bank BRI Syariah.
\end{abstract}

Kata Kunci: bank syariah, iklan, keputusan nasabah, menabung, pelayanan, publisitas

\begin{abstract}
This study aims to determine the effect of service, advertising, and publicity on customer decisions in saving at BRI Syariah Bank. The sampling method in this study using random sampling with a total sample of 100 customers of Bank BRI Syariah Stabat Langkat Regency. The data analysis method used is multiple linear regression analysis. The results of the partially tested research show that service and advertising have a significant effect on customer decisions to save at BRI Syariah Bank, while publicity has no significant effect on customer decisions in saving at BRI Syariah Bank. Simultaneous testing shows that service, advertising, and publicity have a significant effect on customer decisions in saving at BRI Syariah Bank.
\end{abstract}

Keywords: advertising, customer decisions, Islamic banking, publicity, savings, services

\section{PENDAHULUAN \\ Latar Belakang}

Kurangnya sosialisasi dapat menyebabkan market share perbankan syariah masih terbilang rendah, untuk mengatasi masalah tersebut, perbankan syariah perlu untuk melakukan strategi pemasaran yang tepat terhadap produknya. Adapun strategi yang tepat yaitu melalui iklan dan publisitas yang baik, serta diiringi dengan pelayanan yang ramah dan adil kepada nasabah pada semua perbankan syariah di Indonesia (Al-Arif, 2012:10). Dalam melakukan kegiatan pemasaran produk-produk tabungan yang ada pada BRI Syariah kepada masyarakat diperlukan strategi promosi dan kegiatan pelayanan yang sesuai dengan prinsip syariah. Hal ini di lakukan agar masyarakat mengetahui serta memahami berbagai fasilitas dan produk yang ditawarkan pada bank tersebut, sehingga dapat menarik calon nasabah agar mengambil keputusan untuk menggunakan produk atau jasa yang telah di tawarkan sesuai dengan kebutuhan dan keinginannya.

Pelayanan merupakan hal terpenting bagi tiap-tiap unsur bisnis ataupun usaha untuk mencapai satu tujuan utama yaitu kepuasan dan kenyamanan konsumen. Pelayanan adalah 
proses pemenuhan kebutuhan melalui aktivitas manusia secara langsung (Nogi, 2012:208). Selain pelayanan, untuk meningkatkan jumlah nasabah pada suatu bank diperlukan strategi promosi. Adapun strategi promosi yang pertama yaitu iklan. Iklan merupakan bentuk komunikasi secara tidak langsung yang menginformasikan tentang keunggulan dan keuntungan suatu produk (Hermawan, 2012:78). Adapun strategi promosi yang selanjutnya adalah publisitas. Publisitas merupakan kegiatan untuk mempengaruhi kesadaran publik karena agar diperhatikan oleh banyak orang tanpa harus membayar biaya sponsor. Kegiatan publisitas yang biasa dilakukan oleh bank seperti pameran, pembukaan stan promosi di pusat perbelanjaan, sponsorship kegiatan, program Corporate Sosial Responsibility (CSR), mendukung atau berperan serta dalam kegiatan amal seperti penggalangan dana untuk para korban bencana alam, serta kegiatan amal lainnya (Al-Arif, 2012:189).

Dalam menarik calon nasabah atau untuk mempertahankan nasabah yang ada, Bank Syariah perlu memberikan pelayanan yang baik, iklan yang dibuat semenarik mungkin, dan mengadakan kegiatan publisitas tentang produk-produk yang ada pada Bank BRI Syariah. Hal ini dilakukan agar masyarakat luas mengetahui serta memahami berbagai fasilitas dan produk yang ada pada BRI Syariah. Berdasarkan dengan latar belakang masalah di atas, maka peneliti perlu melihat dan mengetahui apakah variabel pelayanan, iklan dan publisitas berpengaruh signifikan terhadap keputusan nasabah menabung. Oleh sebab itu peneliti tertarik untuk membahas tentang bagaimana pengaruh pelayanan, iklan dan publisitas terhadap keputusan nasabah dalam menabung dengan judul "Pengaruh Pelayanan, Iklan dan Publisitas Terhadap Keputusan Nasabah dalam Menabung pada BRI Syariah Stabat Kab. Langkat”.

\section{KERANGKA TEORITS DAN PENGEMBANGAN HIPOTESIS Pelayanan}

Pelayanan (customer service) secara umum adalah setiap kegiatan yang diperuntukkan atau ditujukan untuk memberikan kepuasan kepada pelanggan, melalui pelayanan ini keinginan dan kebutuhan pelanggan dapat terpenuhi. Menurut Tjiptono (2012:78) terdapat lima dimensi service quality, yaitu berwujud (tangibles), kehandalan (reability), ketanggapan (responsiveness), jaminan dan kepastian (assurance), dan empati (emphaty).

\section{Iklan}

Periklanan meliputi semua kegiatan yang terlibat dalam penyajian pesan yang non personal (tidak tertuju pada seseorang tertentu, di suarakan) atau visual dan di biayai secara terbuka untuk suatu produk, jasa atau ide. Pesan yang disampaikan tersebut disebut sebagai iklan yang bisa disiarkan melalui satu atau lebih media dan dibiayai oleh sponsor yang diketahui umum (Shinta, 2011:131).

\section{Publisitas}

Publisitas adalah kegiatan promosi untuk menarik nasabah melalui kegiatan seperti pameran, bakti sosial, perlombaan cerdas cermat, bazar, kuis serta kegiatan lainnya melalui berbagai media (Kasmir, 2018:160). Tolak ukur dalam kegiatan publisitas, yaitu publications (publikasi), identity media (media identitas), events (acara), news (berita), speeches (pidato), 
public-service activities (berperan serta dalam aktivitas sosial), dan sponsorship (pensponsoran) (Musfar, 2020:150).

\section{Pengambilan Keputusan}

Pengambilan keputusan konsumen adalah proses pengintegrasian yang memadukan pengatahuan untuk pengenalan dua prilaku alternatif atau lebih, dan memilih salah satu diantaranya. Hasil dari pengintegrasian ini adalah suatu pilihan yang ditampilkan secara kognitif sebagai keinginan dalam berperilaku (Sangadji, 2013:121). Adapun keputusan adalah pilihan suatu tindakan dari dua atau lebih alternatif. Dengan kata lain orang yang mengambil keputusan harus memiliki satu pilihan dari beberapa pilihan alternatif yang ada. Bila seseorang dihadapkan pada dua pilihan, yaitu membeli dan tidak membeli, dan kemudian dia memilih membeli, maka dia ada dalam posisi membuat keputusan.

\section{Penelitian Terdahulu}

(Yani, 2018) meneliti tentang pengaruh promosi dan kualitas pelayanan terhadap keputusan minat calon nasabah (studi pada BRI Syariah kantor cabang Kedaton Bandar Lampung) dengan sampel yang digunakan adalah simple random sampling dengan sampel 78 orang nasabah dan analisis data penelitian menggunakan analisis regresi linier berganda dengan menggunakan program aplikasi IBM SPSS statistics 21. Berdasarkan hasil pengujian menunjukkan bahwa adanya pengaruh promosi terhadap minat calon nasabah BRI Syariah, adanya pengaruh kualitas pelayanan terhadap minat calon nasabah BRI Syariah. Adanya pengaruh promosi dan kualitas pelayanan secara simultan terhadap minat calon nasabah BRI Syariah.

(Ashariansyah, 2018) meneliti tentang pengaruh periklanan (advertising), publisitas (publicity), dan penjualan pribadi (personal selling) terhadap keputusan nasabah menabung pada Bank SUMSEL Babel Cabang Syariah Palembang. Penelitian ini termasuk pada jenis penelitian lapangan dengan menggunakan metode kuantitatif. sumber data yang digunakan dalam penelitian ini yaitu data primer, yang diperoleh dari hasil penyebaran kuesioner kepada 100 responden. Teknik pengambilan sampel yang digunakan adalah insidental sampling. Teknik analisis data dilakukan dengan analisis regresi berganda. Hasil penelitian ini menunjukkan bahwa adanya pengaruh positif dan signifikan dari masing-masing variabel independen, yaitu periklanan, publisitas, dan penjualan pribadi terhadap variabel dependen, yaitu keputusan nasabah. Adanya pengaruh positif dan signifikan antara variabel periklanan (advertising), publisitas (publicity), dan penjualan pribadi (personal selling) secara simultan terhadap keputusan nasabah.

(Haris \& $\mathrm{T}, 2012$ ) meneliti tentang pengaruh kualitas pelayanan dan periklanan terhadap keputusan nasabah dalam menabung pada Bank Syariah (studi kasus pada BTN Syariah Surakarta). Penelitian ini bertujuan untuk menganalisis pengaruh kualitas pelayanan dan periklanan secara parsial dan simultan terhadap keputusan nasabah dalam menabung pada Bank Tabungan Negara (BTN) Syariah Surakarta. Populasi dalam penelitian ini adalah jumlah nasabah yang menabung di Bank Tabungan Negara (BTN) Syariah Surakarta dan menggunakan Accidental Sampling sebagai metode pengambilan sampel (jumlah sampel 98 responden). Alat analisis yang digunakan dalam penelitian ini adalah regresi linier berganda, 
yang sebelumnya telah dilakukan uji validitas dan reliabilitas serta uji asumsi klasik. Berdasarkan pengujian secara parsial kualitas pelayanan dan periklanan memiliki pengaruh yang signifikan secara positif.

\section{Model Penelitian}

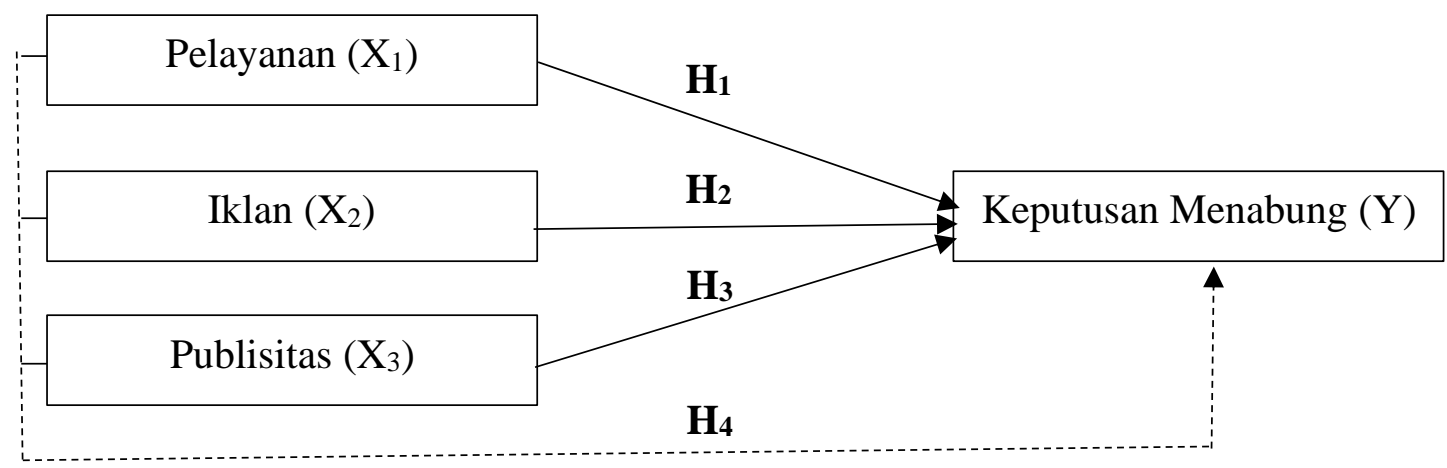

Gambar 1. Model Penelitian

\section{Hipotesis}

Sumber: Kajian Teoretik

$\mathrm{H}_{1}$ : Pelayanan berpengaruh positif terhadap keputusan nasabah dalam menabung di Bank BRI Syariah Stabat.

$\mathrm{H}_{2}$ : Iklan berpengaruh positif terhadap keputusan nasabah dalam menabung di Bank BRI Syariah Stabat.

$\mathrm{H}_{3}$ : Publisitas berpengaruh positif terhadap keputusan nasabah dalam menabung di Bank BRI Syariah Stabat.

$\mathrm{H}_{4}$ : Pelayanan, iklan, dan publisitas berpengaruh positif terhadap keputusan nasabah dalam menabung di Bank BRI Syariah Stabat.

\section{METODE PENELITIAN}

\section{Pendekatan Penelitian}

Penelitian ini termasuk dalam kategori penelitian asosiatif kausal dengan menggunakan pendekatan kuantitatif. Metode penelitian kuantitatif menggunakan data numerik pengukuran hasil yang objektif menggunakan analisis statistik. Adapun metode analisis dalam penlitian ini menggunakan analisis regresi linear berganda.

\section{Populasi, Sampel dan Teknik Sampling}

Populasi dalam penelitian ini yaitu nasabah yang menabung di Bank BRI Syariah Stabat. Karena jumlah populasinya tidak diketahui, maka peneliti mengambil 100 responden untuk penelitian ini. Pengambilan sampel dalam penelitian ini adalah menggunakan teknik random sampling. 


\section{Jenis dan Sumber Data}

Data yang digunakan dalam penelitian ini adalah data primer dan sekunder. Data primer yang diperoleh dengan menyebarkan kuesioner dan data sekunder adalah data yang diperoleh berupa bukti catatan informasi tertulis dan dokumentasi di Bank BRI Syariah Stabat.

\section{Teknik Pengumpulan Data}

Teknik pengumpulan data dalam penelitian ini yaitu dengan menyebarkan kuesioner kepada nasabah yang menabung di Bank BRI Syariah Stabat.

\section{Pengujian Instrumen Penelitian}

Pengujian instrument pada penelitian ini dilakukan berdasarkan uji validitas dan uji reliabilitas, dengan menggunakan program SPSS.

\section{Teknik Analisis}

Metode analisis yang digunakan dalam penelitian ini adalah regresi linear berganda. Digunakan untuk menganalisa pengaruh beberapa variabel bebas atau independen terhadap variabel terikat atau dependen. Dalam pengolahan data menggunakan program aplikasi SPSS.

\section{Analisis Regresi Linear Berganda}

Analisis regresi adalah suatu analisis yang berfungsi untuk mengukur pengaruh variabel bebas terhadap variabel terikat. Jika pengukuran pengaruh antar variabel melibatkan lebih dari satu variabel bebas $\left(\mathrm{X}_{1}, \mathrm{X}_{2}, \mathrm{X}_{3}, \ldots, \mathrm{X}_{\mathrm{n}}\right)$ dinamakan regresi linear berganda, dikatakan linear karena setiap estimasi atas nilai diharapkan mengalami peningkatan atau penurunan mengikuti garis lurus. Persamaan regresi dalam penelitian ini:

$$
Y=\alpha+\beta_{1} X_{1}+\beta_{2} X_{2}+\beta_{3} X_{3}+e
$$

$\begin{array}{ll}\text { Keterangan: } & \\ \mathrm{Y} & : \text { Keputusan menabung } \\ \alpha & : \text { Konstanta } \\ \beta_{1}, \beta_{2}, \beta_{3} & : \text { Koefisien regresi } \\ \mathrm{X}_{1} & : \text { Pelayanan } \\ \mathrm{X}_{2} & \text { : Iklan } \\ \mathrm{X}_{3} & : \text { Publisitas } \\ \mathrm{e} & : \text { error }\end{array}$




\section{HASIL PENELITIAN DAN PEMBAHASAN}

Tabel 1. Hasil Uji Validitas

\begin{tabular}{|c|c|c|c|c|}
\hline Variabel & Item Pernyataan & Rhitung & $\mathbf{R}_{\text {tabel }}$ & Keterangan \\
\hline \multirow{5}{*}{$\begin{array}{c}\text { Keputusan } \\
\text { Menabung } \\
\text { (Y) }\end{array}$} & $\mathrm{Y} 1$ & 0.675 & 0.195 & Valid \\
\hline & $\mathrm{Y} 2$ & 0.740 & 0.195 & Valid \\
\hline & $\mathrm{Y} 3$ & 0.699 & 0.195 & Valid \\
\hline & $\mathrm{Y} 4$ & 0.545 & 0.195 & Valid \\
\hline & Y5 & 0.639 & 0.195 & Valid \\
\hline \multirow{5}{*}{$\begin{array}{l}\text { Pelayanan } \\
\left(\mathrm{X}_{1}\right)\end{array}$} & $\mathrm{X} 1.1$ & 0.677 & 0.195 & Valid \\
\hline & $\mathrm{X} 1.2$ & 0.641 & 0.195 & Valid \\
\hline & $\mathrm{X} 1.3$ & 0.752 & 0.195 & Valid \\
\hline & $\mathrm{X} 1.4$ & 0.614 & 0.195 & Valid \\
\hline & $\mathrm{X} 1.5$ & 0.592 & 0.195 & Valid \\
\hline \multirow{4}{*}{$\begin{array}{c}\text { Iklan } \\
\left(\mathrm{X}_{2}\right)\end{array}$} & $\mathrm{X} 2.1$ & 0.627 & 0.195 & Valid \\
\hline & $\mathrm{X} 2.2$ & 0.758 & 0.195 & Valid \\
\hline & $\mathrm{X} 2.3$ & 0.835 & 0.195 & Valid \\
\hline & $\mathrm{X} 2.4$ & 0.735 & 0.195 & Valid \\
\hline \multirow{7}{*}{ Publisitas $\left(\mathrm{X}_{3}\right)$} & X3.1 & 0.824 & 0.195 & Valid \\
\hline & X3.2 & 0.809 & 0.195 & Valid \\
\hline & X3.3 & 0.777 & 0.195 & Valid \\
\hline & X3.4 & 0.789 & 0.195 & Valid \\
\hline & $\mathrm{X} 3.5$ & 0.734 & 0.195 & Valid \\
\hline & X3.6 & 0.737 & 0.195 & Valid \\
\hline & X3.7 & 0.837 & 0.195 & Valid \\
\hline
\end{tabular}

Sumber: Output SPSS, 2021

Berdasarkan Tabel 1. bahwa seluruh item pernyataan yang digunakan untuk mengukur variabel keputusan menabung, pelayanan, iklan, dan publisitas adalah valid, karena masingmasing pernyataan tersebut memiliki $\mathrm{R}_{\text {hitung }}$ lebih besar atau sama dengan $\mathrm{R}_{\text {tabel}}$.

Tabel 2. Hasil Uji Reliabilitas

\begin{tabular}{cccc}
\hline Variabel & Cronbach's Alpha & Cut off & Kesimpulan \\
\hline Pelayanan & 0.694 & 0,60 & Reliabel \\
\hline Iklan & 0.703 & 0,60 & Reliabel \\
\hline Publisitas & 0.896 & 0,60 & Reliabel \\
\hline Keputusan Menabung & 0.682 & 0,60 & Reliabel \\
\hline
\end{tabular}

Sumber: Output SPSS (2021)

Berdasarkan Tabel 2 menunjukkan bahwa setiap variabel mempunyai nilai cronbach's alpha lebih dari $60(\alpha \geq 0,60)$ sehingga data tersebut dapat dikatakan reliabel. 


\section{Uji Asumsi Klasik \\ Uji Normalitas}

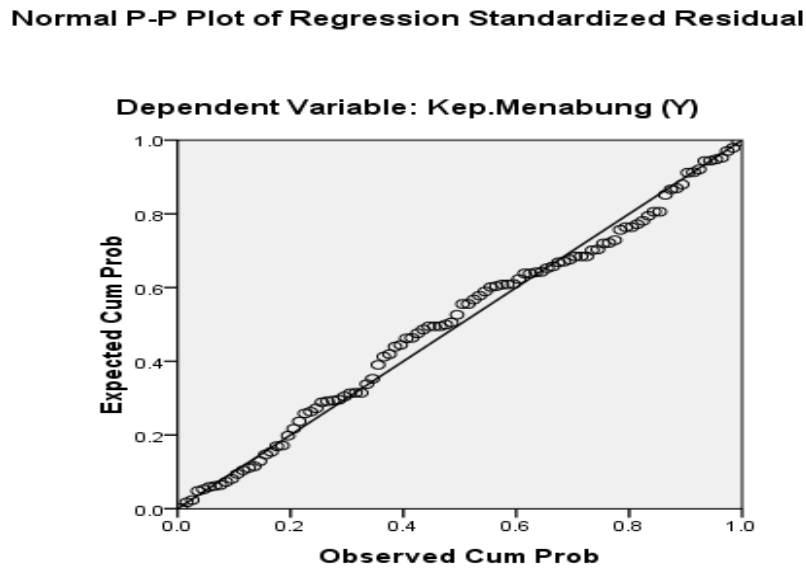

Gambar 1. Grafik P-P Plot

Sumber: SPSS, Olah Data (2021)

Berdasarkan gambar 1 dapat disimpulkan bahwa kurva normal p-plot terlihat tititktitiknya menyebar disekitar garis diagonal dan penyebarannya tidak terlalu jauh atau melebar. Berarti kurva menunjukkan bahwa model regresi memenuhi asumsi normalitas dan model regresi layak untuk menganalisa pengaruh variabel pelayanan, iklan, dan publisitas terhadap pengambilan keputusan.

\section{Uji Multikoleniaritas}

Tabel 3. Hasil Uji Multikoleniaritas

\begin{tabular}{lrrrr}
\hline & \multicolumn{3}{c}{ Unstandardized Coefficients } & \multicolumn{2}{c}{ Collinearity Statistics } \\
Model & $\mathrm{B}$ & Std. Error & Tolerance & \multicolumn{1}{c}{ VIF } \\
\hline 1 (Constant) & 3.336 & 2.348 & & \\
Pelayanan $\left(\mathrm{X}_{1}\right)$ & .458 & .081 & .866 & 1.155 \\
Iklan $\left(\mathrm{X}_{2}\right)$ & .330 & .110 & .827 & 1.209 \\
Publisitas $\left(\mathrm{X}_{3}\right)$ & .080 & .048 & .943 & 1.060 \\
\hline
\end{tabular}

Sumber: SPSS, Olah Data (2021)

Berdasarkan tabel 3, masing-masing nilai variabel independen, yaitu untuk variabel pelayanan $\left(\mathrm{X}_{1}\right)$ memiliki nilai Tolerance 0,866 dan nilai VIF 1,155 , variabel iklan $\left(\mathrm{X}_{2}\right)$ memiliki nilai Tolerance 0,827 dan nilai VIF 1,209, variabel publisitas $\left(\mathrm{X}_{3}\right)$ memiliki nilai Tolerance 0,943 dan nilai VIF 1,060. Karena nilai Tolerance > 0,10 dan nilai VIF < 10 maka dapat disimpulkan bahwa model regresi dinyatakan tidak terjadi multikolinearitas. 


\section{Uji Heteroskedastisitas}

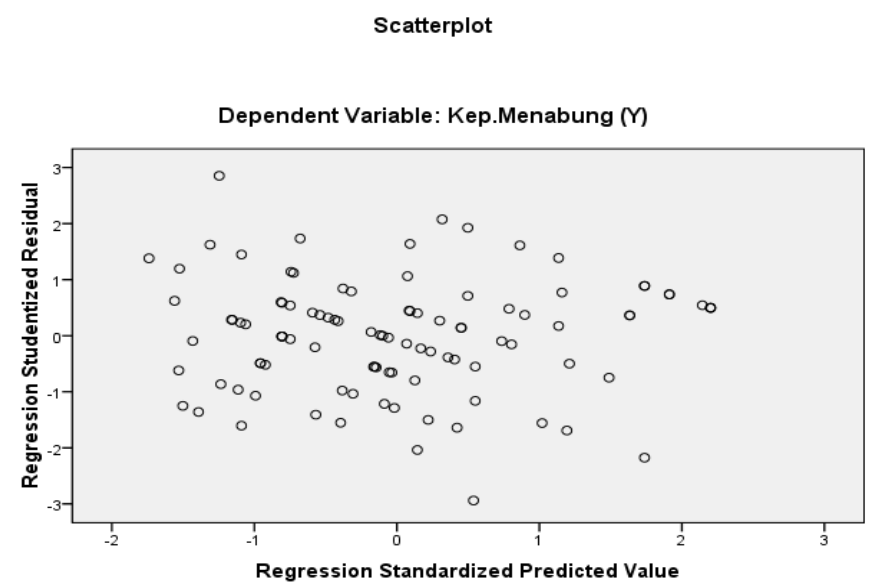

Gambar 2. Grafik Scatterplot

Sumber: SPSS, Olah Data (2021)

Dari gambar 2 terlihat bahwa distribusi data tidak teratur dan tidak membentuk pola tertentu, serta menyebar diatas dan di bawah angka nol pada angka nol pada sumbu Y. Hal ini dapat disimpulkan bahwa tidak terjadi heteroskedastisitas pada model regresi.

\section{Uji Analisis Regresi Linear Berganda}

Tabel 4. Analisis Regresi Linear Berganda

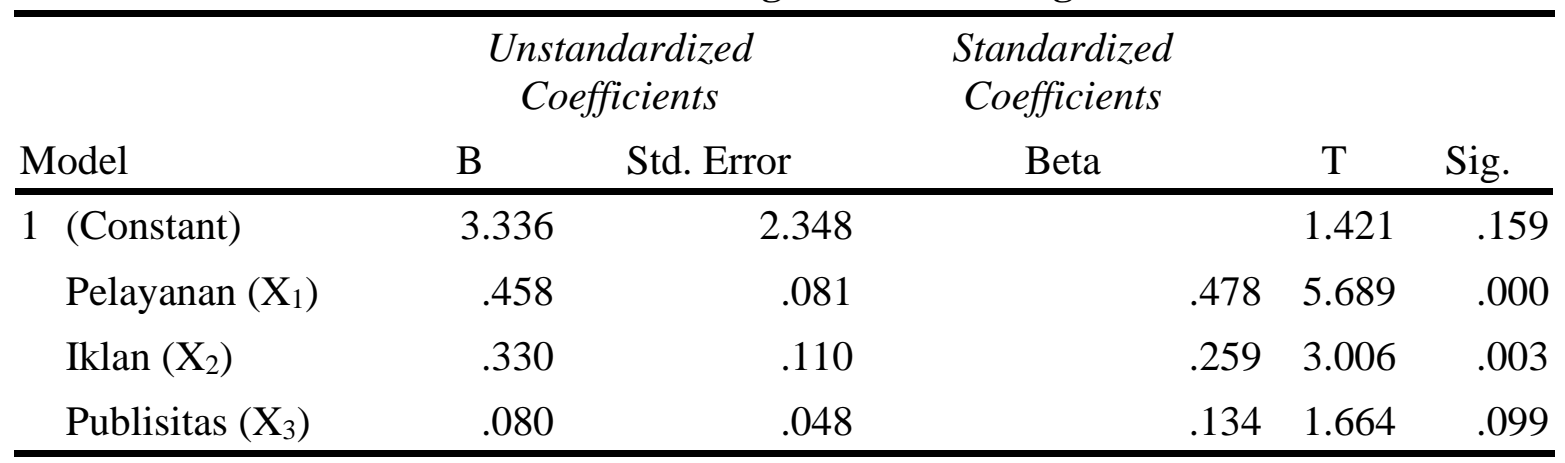

Sumber: SPSS, Olah Data (2021)

Berdasarkan uji t pada tabel 4, maka hasil dari uji analisis uji t dapat dijelaskan sebagai berikut:

1. Hasil analisis uji t menunjukkan bahwa variabel pelayanan yang diperoleh nilai dari thitung sebesar 5,689> 1,984 dengan hasil dari signifikansi $0,00<0,05$, maka $\mathrm{H}_{0}$ ditolak dan $\mathrm{H}_{\mathrm{a}}$ diterima, serta variabel pelayanan memiliki nilai koefisien beta sebesar 0,458 , yang berarti apabila pelayanan naik satu satuan maka keputusan menabung akan menurun sebesar 0,458, maka dapat diambil kesimpulan bahwa variabel pelayanan memiliki pengaruh signifikan terhadap keputusan menabung di BRI Syariah Stabat.

2. Hasil analisis uji t menunjukkan bahwa variabel iklan yang diperoleh nilai $t_{\text {hitung }}$ sebesar 3,006 > 1,984 dengan hasil dari signifikansi $0,03<0,05$, maka $\mathrm{H}_{0}$ ditolak dan $\mathrm{H}_{\mathrm{a}}$ diterima, serta variabel iklan memiliki nilai koefisien beta sebesar 0,330 yang berarti apabila iklan naik satu satuan maka keputusan menabung akan menurun sebesar 0,330. Dari sini dapat 
diambil kesimpulan bahwa variabel iklan memiliki pengaruh signifikan terhadap keputusan menabung di BRI Syariah Stabat.

3. Hasil uji t menunjukkan bahwa variabel publisitas yang diperoleh dari nilai thitung sebesar 1,664 < 1,984 dengan hasil signifikansi sebesar 0,099 > 0,05, maka $\mathrm{H}_{0}$ diterima dan $\mathrm{H}_{\mathrm{a}}$ ditolak, serta variabel publisitas memiliki nilai koefisien beta sebesar 0,080 yang berarti apabila publisitas naik satu satuan, maka keputusan menabung akan menurun sebesar 0,080. Hal ini dapat disimpulkan bahwa variabel publisitas tidak memiliki pengaruh terhadap keputusan menabung di BRI Syariah Stabat.

Tabel 5. Hasil Uji Simultan

\begin{tabular}{|c|c|c|c|c|c|c|}
\hline \multicolumn{2}{|c|}{ Model } & \multirow{2}{*}{$\frac{\text { Sum of Squares }}{190.374}$} & \multirow{2}{*}{$\frac{\mathrm{df}}{3}$} & \multirow{2}{*}{$\frac{\text { Mean Square }}{63.458}$} & \multirow{2}{*}{$\frac{F}{22.424}$} & \multirow{2}{*}{$\frac{\text { Sig. }}{.000^{\mathrm{a}}}$} \\
\hline 1 & Regression & & & & & \\
\hline & Residual & 271.666 & 96 & 2.830 & & \\
\hline & Total & 462.040 & 99 & & & \\
\hline
\end{tabular}

Sumber: SPSS, Olah Data (2021)

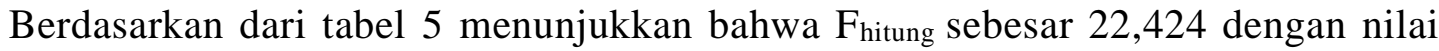
signifikansi 0,000 , maka hasil ini dapat dibandingkan dengan nilai $F_{\text {tabel }}$ dengan menggunakan taraf signifikansi 0,05. Maka dapat disimpulkan bahwa $\mathrm{H}_{0}$ ditolak apabila model regresi signifikan dan berpengaruh secara bersama-sama, hal ini dapat dilihat nilai df1 = k-1 (3-1) dan df $2=\mathrm{n}-\mathrm{k}(100-3=97)$. Sehingga hasil yang diperoleh dari $\mathrm{F}_{\text {hitung }}>$ $F_{\text {tabel }}$ yaitu sebesar 22,424 $>3,09$, dengan taraf signifikan sebesar 0,000 < 0,05, yang dapat disimpulkan bahwa $\mathrm{H}_{0}$ ditolak dan $\mathrm{H}_{\mathrm{a}}$ diterima. Maka dapat disimpulkan bahwa variabel bebas (pelayanan, iklan, dan publisitas) secara simultan memiliki pengaruh signifikan terhadap variabel terikat (keputusan menabung) di BRI Syariah Stabat.

\section{PEMBAHASAN}

\section{Pengaruh Pelayanan Terhadap Keputusan Menabung di BRI Syariah Stabat}

Dari hasil olahan data dengan menggunakan SPSS menunjukkan koefisien regresi variabel pelayanan berpengaruh positif dan signifikan terhadap variabel keputusan menabung, hal ini dibuktikan dengan hasil dari koefisien regresi sebesar 0,458 dan $t_{\text {hitung }}$ sebesar 5,689 terhadap tingkat keputusan menabung di BRI Syariah Stabat. Hal ini menunjukkan bahwa pelayanan memiliki pengaruh yang positif dan signifikan terhadap keputusan menabung di BRI Syariah Stabat, pelayanan yang diberikan pihak bank terutama customer service adalah dengan bersikap ramah dimana mereka melayani nasabahnya agar merasa nyaman ketika melakukan aktivitas yang berhubungan dengan perbankan seperti pembukaan buku rekening baru, konsultasi tentang produk, keluhan dan lainnya yang diawali dengan memberikan salam kepada nasabah. Penelitian ini sesuai dengan teori yang diungkapkan oleh Nogi (2012), yang mengatakan pelayanan adalah proses pemenuhan kebutuhan melalui aktivitas orang lain secara langsung. Yang bertujuan memberikan rasa nyaman dan kepercayaan kepada nasabah untuk mempercayakan dananya serta menghasilkan keputusan nasabah untuk menabung. 
Diperkuat juga oleh penelitian terdahulu yang dilakukan oleh (Maulida, 2016) yang berjudul "Analisis pengaruh promosi dan pelayanan terhadaap minat nasabah menabung pada BMT Taruna Sejahtera Cabang Tuntang" yang menyatakan bahwa adanya pengaruh positif dan signifikan dari variabel promosi dan pelayanan terhadap minat nasabah menabung pada BMT Taruna Sejahtera Cabang Tuntang.

\section{Pengaruh Iklan Terhadap Keputusan Menabung di BRI Syariah Stabat}

Pada koefisien regresi menyatakan bahwa iklan berpengaruh positif dan signifikan dan sesuai pernyataan hipotesis bahwa $\mathrm{H}_{0}$ ditolak dan $\mathrm{H}_{\mathrm{a}}$ diterima dengan nilai koefisien 0,330 terhadap keputusan menabung di BRI Syariah Stabat. Dengan ini dapat disimpulkan bahwa apabila terjadi peningkatan iklan sebesar $1 \%$ maka akan menaikkan jumlah keputusan nasabah menabung di BRI Syariah Stabat. Hasil penelitian ini sesuai dengan penelitian terdahulu yang dilakukan oleh Rahayu (2017) dengan judul "pengaruh promotional mix syariah terhadap proses keputusan nasabah dalam memilih tabungan" yang menyatakan bahwa iklan berpengaruh secara positif dan signifikan terhadap keputusan menabung. BRI Syariah biasa mengiklankan produknya melalui media elektronik seperti televisi, radio, website dan media sosial serta media cetak bisa melalui koran, brosur, dan banner. Karena dengan melakukan periklanan melalui media elektronik dan media cetak, Bank bisa mempengaruhi keputusan nasabah untuk menabung di BRI Syariah Stabat.

\section{Pengaruh Publisitas Terhadap Keputusan Menabung Di BRI Syariah Stabat}

Pada koefisien regresi menyatakan bahwa publisitas tidak berpengaruh sesuai pernyataan hipotesis bahwa $\mathrm{H}_{0}$ diterima dan $\mathrm{H}_{\mathrm{a}}$ ditolak dengan nilai koefisien 0,080 terhadap keputusan menabung di BRI Syariah Stabat. Hasil dari olahan data penelitian ini tidak sesuai dengan hipotesis penelitian yang menyatakan bahwa adanya pengaruh dan signifikan variabel publisitas terhadap keputusan menabung di BRI Syariah Stabat, atau dengan kata lain $\mathrm{H}_{0}$ diterima dan $\mathrm{H}_{\mathrm{a}}$ ditolak. Hal ini sesuai dengan pernyataan bahwa publisitas tidak berpengaruh terhadap keputusan menabung di BRI Syariah Stabat. Hal ini sesuai dengan hasil wawancara dengan salah satu nasabah BRI Syariah Stabat yang menyatakan bahwa ketika mengadakan acara pameran/bazar yang diselenggarakan oleh pihak BRI Syariah Stabat ataupun acara khusus seperti HUT Langkat yang biasanya selalu diikuti oleh stand bazar dari BRI Syariah Stabat memang selalu sedikit dalam menarik perhatian pengunjung. Apalagi dimasa pandemi sekarang, acara bazar sudah tidak dilakukan lagi.

\section{KESIMPULAN, KETERBATASAN DAN SARAN}

Penelitian ini bertujuan untuk mengetahui pengaruh pelayanan, iklan, dan publisitas terhadap keputusan nasabah dalam menabung di BRI Syariah Stabat dengan menggunakan metode analisis regresi linear berganda maka dapat ditarik kesimpulan bahwa Pelayanan dan iklan secara parsial berpengaruh signifikan terhadap keputusan menabung pada BRI Syariah Stabat, sedangkan Publisitas secara parsial tidak berpengaruh signifikan terhadap keputusan menabung pada BRI Syariah Stabat. Selanjutnya Pelayanan, iklan, dan publisitas berpengaruh secara simultan terhadap keputusan menabung pada BRI Syariah Stabat. 
Penelitian ini masih memiliki beberapa keterbatasan yang dapat diperbaiki oleh peneliti selanjutnya. Salah satu keterbatasan adalah pemilihan sampel atau responden sebagai sumber referensi yang masih terbatas. Penelitian selanjutnya diharapkan lebih mempersiapkan diri dalam proses pengambilan dan pengumpulan serta segala sesuatunya sehingga penelitian dapat dilaksanakan dengan lebih baik. Untuk penelitian selanjutnya diharapkan juga mencari sumber wawancara yang lebih kompeten dalam kajian keputusan menabung pada BRI Syariah Stabat.

\section{DAFTAR PUSTAKA}

Al-Arif, M.N. Dasar-Dasar Pemasaran Bank Syariah. Bandung: Alfabeta, 2012.

Ashariansyah, N. (2018). Analisis Pengaruh Promosi dan Kualitas Pelayanan Terhadap Keputusan Minat Calon Nasabah (Studi pada BRI Syariah Kantor Cabang Kedaton Bandar Lampung) [Tesis]. Palembang (ID): UIN Raden Fatah.

Haris, H., \& T, N. S. I. (2012). Pengaruh Kualitas Pelayanan dan Periklanan terhadap Keputusan Nasabah dalam Menabung pada Bank Syariah (Studi Kasus pada BTN Syariah Surakarta). Muqtasid: Jurnal Ekonomi Dan Perbankan Syariah, 3(1), 1-24. https://doi.org/10.18326/MUQTASID.V3I1.1-24

Hermawan. (2012). Komunikasi Pemasaran. Jakarta: Erlangga.

Kasmir. (2018). Manajemen Perbankan. Jakarta: Kencana.

Maulida, Isnaine. (2016). Analisis Pengaruh Promosi dan Pelayanan terhadap Minat Nasabah Menabung pada BMT Taruna Sejahtera Cabang Tuntang [Tesis]. Salatiga (ID): IAIN Salatiga.

Musfar, Tengku Firli. (2020). Manajemen Pemasaran, Bandung: CV. Media Sains Indonesia. Nogi, Hessel S., Tangkilisan. (2012). Manajemen Publik. Bandung: Alfabeta.

Rahayu, Selvia Sri Puji. (2017). Pengaruh Promotional Mix Syariah Terhadap Proses Keputusan Nasabah Dalam Memilih Tabungan (Studi Kasus Pada Tabungan Faedah PT Bank BRI Syariah) [Tesis]. Jakarta (ID): UIN Syarif Hidayatullah.

Sangadji, M.E. (2013). Perilaku Konsumen. Yogyakarta: CV Andi Offset.

Shinta, Agustina. (2011). Manajemen Pemasaran, Malang: UB Press.

Tjiptono, Fandy. (2008). Strategi Pemasaran. Yogyakarta: ANDI.

Yani, P.A. (2018). Analisis Pengaruh Promosi dan Kualitas Pelayanan terhadap Keputusan Minat Calon Nasabah (Studi pada BRI Syariah Kantor Cabang Kedaton Bandar Lampung) [Tesis]. Lampung (ID): UIN Raden Intan. 